\title{
Can Strengths-Based Interventions be used to Support the Financial Wellbeing of Tertiary Students in Financial Need During COVID-19?
}

\author{
Robyn Angus \\ Financial Counsellor \\ La Trobe University Student Union \\ La Trobe University, Australia
}

\begin{abstract}
Positive Psychology explores how professionals and individuals, including financial counsellors, can make life "better", instead of merely alleviating suffering (Seligman \& Csikszenzentmihalyi, 2000). It is acknowledged that some financial problems are insurmountable, and students can lack motivation due to continual disadvantage, discrimination, overwhelming circumstances and poverty. Positive Psychology encourages professionals to seek out the strengths of character demonstrated by our clients; to acknowledge past achievements and encourage and build greater self-determination and a sustainable financial future. Positive Psychology research is evidencebased and applied in many settings (Lyubomirsky \& Sin, 2009). Financial counsellors do not profess to be psychologists, but insight fostered by psychological knowledge and interventions may enlighten our engagement, and/or facilitate referrals to other professionals. Clients experiencing financial difficulty often understand their issues best and may possess strengths to endure hardship and move towards a sustainable financial future. Some practical tools are offered to add to professional practice and to offer some hope during the COVID-19 pandemic and into the recovery period.
\end{abstract}

\section{Keywords}

University, Positive Psychology, strength-based practice, financial counselling

\section{Introduction}

The issues affecting students at La Trobe University, Student Union (LTSU) during COVID19 are wide ranging and similar to those found in the wider community. Issues presented by students during 2020 include concerns of a psychological, social, physical and financial nature (Shukla, 2020). Clearly, demand for financial assistance from the community sector and government has sharply risen at this time (CDS Database, Advocacy Dep't, LTSU., 2020). Because of the government response to the pandemic, employment has been both uncertain and vulnerable to layoffs. Whilst governments at Federal and State level have layered economic support designed to maintain business and employment viability there have been disparities of benefit. Job Seeker and Job Keeper benefits have certainly helped affected domestic students. However some casual workers and international students were ineligible and have had to seek emergency relief from other sources (CDS Database, Advocacy Dep't, LTSU., 2020). LTSU data highlight that insecure accommodation and affordability of rent is also a problem, as is eligibility and access to rental subsidies,. Many international students are ineligible for Centrelink support and failed to gain University assistance due to the high demand for limited funds. In an SBS News article Florez (2020) reported on a survey of temporary visa holders and their plights which included job losses for $65 \%$ of respondents and not having enough money for basic needs identified by $39 \%$ of respondents. A further $34 \%$ of respondents identified as homeless or at risk of homelessness due to an inability to pay their rent. These statistics strengthen the call for Universities to respond to these immediate needs experienced by students on temporary visas whose employment disappeared in the COVIDeconomy.

This discussion will outline the meaning of Positive Psychology, and how it can be applied in financial counselling. Self Determination Theory is particularly useful for highlighting the 
elements of autonomy, competence and relatedness as supportive of improvement in student wellbeing. The discussion raises interventions in casework, financial literacy and community connection to encourage greater self-determination and wellbeing. Several free resources are shared to benefit others in this field including mindfulness and meditation resources.

\section{How can Positive Psychology inform our practice?}

Positive Psychology is evidence-based practices used in personal and professional settings to make life better and to improve wellbeing. Research has shown positive outcomes are fostered when an individual is encouraged to concentrate on strength interventions, in preference to more traditional methods of addressing problems (Seligman \& Csikszenzentmihalyi, 2000). Such a strengths-based approach can be used to identify client character strengths and are readily applied in the university setting (Wade, Marks, \& Hetzel, 2015).

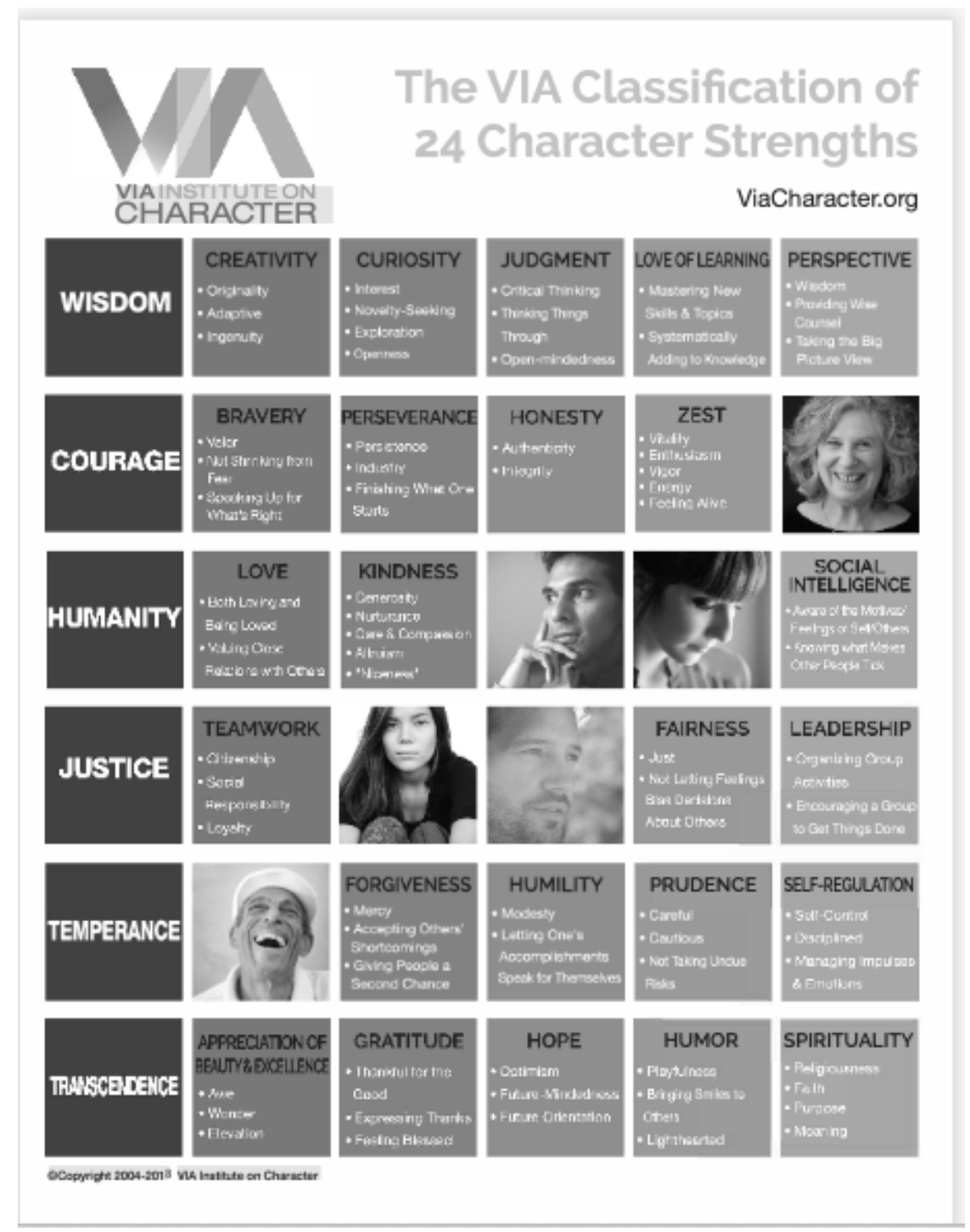

Figure.1: (VIA Institute of Character, 2020)

Professor Martin Seligman is a Professor of Psychology (University of Pennsylvania's Department of Psychology) and President of The American Psychological Association. He is best known for this 'strengths-based' approach. The Values in Action Inventory (VIA) (Figure 1) is a free self-assessment tool used to self-identify strengths such as gratitude, hope and curiosity (Niemiec, 2018). These strengths can be identified in our clients as well as in 
practitioners. The resilience and honesty of a student who recognises their long-term financial problem and seeks help is to be honoured and nurtured. Acknowledging these positive attributes can build rapport and provide a firm foundation for client-centred casework. Financial terminology such as debt, fines, bankruptcy and budgeting can raise anxiety and dread for many students. Instead, a strengths-based approach will address these same issues from a positive angle. Examples of a positive strengths lead approach include focussing on the desire to better manage credit, avoid fines and establish sound goal setting. A strengths focus alone cannot solve a student's situation, however building a foundation of hope by opening options for new possibilities stands in contrast to indulging past scenarios, reinforcing current fears, attribution of blame and a litany of negative self-judgement.

\section{A research-based approach to achieving greater well-being}

Extending the focus on strengths building, Ryan and Deci (2000) introduced SelfDetermination Theory (SDT) and identified three elements: autonomy, competence and relatedness, which they state provides a pathway towards greater wellbeing. Conversely, the absence of these elements produces a challenge to achieve wellbeing. Research has shown these three elements to be crucial to the enabling of greater wellbeing (Ryan \& Deci, 2000). It is possible to integrate these elements into financial counselling to encourage a more sustainable financial future, and ultimately enhance general wellbeing. Practitioners are encouraged to reflect on the degree to which these three elements of autonomy, competence and relatedness are present in their practice.

\section{Autonomy and motivation to achieve financial goals}

According to SDT, if a student's level of autonomy is high, their motivation to improve their situation will make wellbeing more likely. However, if a student is attending financial counselling only because they have been told to, their engagement in the process is likely to fall away or fail. Can practitioners of financial counselling build more client autonomy, selfdriven motivation and responsibility to set goals? Is this even possible if the financial counsellor's client has been criticised, blamed and shamed with multiple issues over many years and lost confidence and all sense of self-determination? It is likely that students with long-term disadvantage and/or mental health conditions will experience low self-esteem and/or loss of confidence and will not find the essential self- motivation. Such students will need effective advocacy combined with frequent on-going support in the short to mid-term.

\section{Resources and skills to build competence and confidence}

In addition to possessing autonomous motivation, the second element of SDT involves the competence and confidence to succeed. Clients receiving financial counselling can benefit from greater financial skills and resources, otherwise known as financial capability. A university is an ideal learning environment to embed an educational program outlining skills needed for financial capability. Positive psychology, strengths based approaches and STD can be fostered by leaning into the students' love of learning and academic capability (Wade, Marks, \& Hetzel, 2015). Conversely, a lack of financial skills and limited access to financial education resources leaves students at greater risk of suffering from unnecessary debt and financial scams.

Many resources and educational programs are free of charge, such as Money Smart (ASIC, 2020). Student issues presented at LTSU are most typically budgeting, debt management, payment of University fees, engagement with Centrelink and responding to taxation requirements (CDS Database, Advocacy Dep't, LTSU., 2020). Modules comparable to those developed by LTSU using ASIC information as highlighted in Figure 2 (ASIC, 2020) (LTSU, 2020) could be used to instil skills and confidence for students and could be adapted for other 
client groups such as the elderly, disabled or those with addictive behaviours. These financial capability building programs guide client skill development and provide access to resources which in turn, fosters confidence and feelings of autonomy and self-determination.

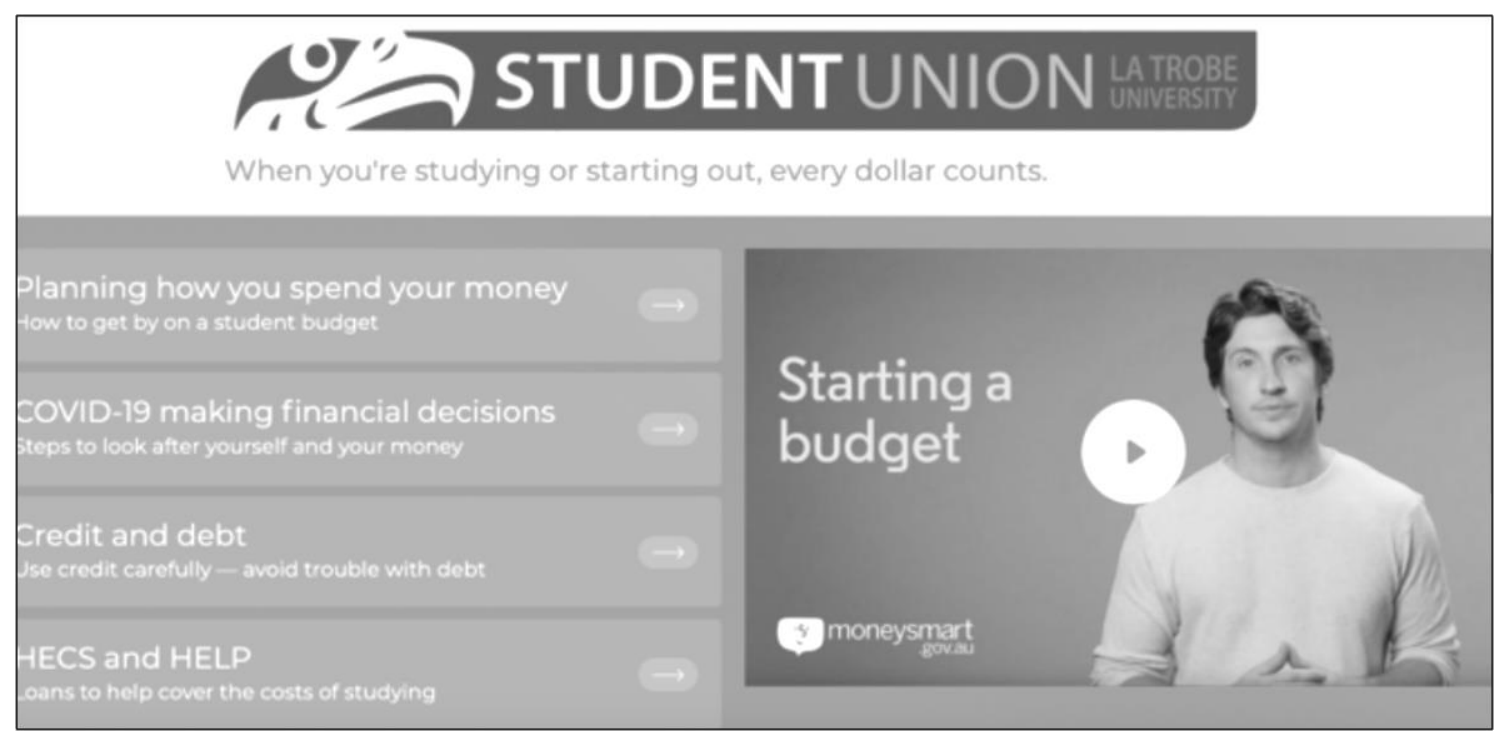

Figure. 2. ASIC Information

The LTSU educational modules for financial literacy and wellbeing delivered in an online teaching format are ideal for university students and have proven to be far more effective than conducting group face-to-face sessions where student interest was high but attendance unpredictable and sporadic (CDS Database, Advocacy Dep't, LTSU., 2020). The most suitable external resources for university students identified was the ASIC Money Smart website being both objective and free; it is provided and maintained by the Australian Government. The most popular topics accessed by university students have been: Budgeting, Debt Management, Superannuation, Tax and Understanding Scams (La Trobe University, Student Union, 2020). Additional financial capability educational resources are Money Smart ${ }^{1}$ and Financial Basics Foundation. $^{2}$

\section{Benefits of support, community links, and relatedness}

According to SDT the third element necessary to activate greater wellbeing is through a focus on relatedness. Relatedness is obvious to financial counsellors who work in community organisations and foster relationships to encourage and support those who experience more isolation. However, for some during the COVID-19 lockdowns there was not ready access to those with whom they had a supportive relationship, and this had serious consequences including increased experiences of symptoms of anxiety and depression. The need to build relatedness is crucial and is especially so for students of culturally diverse backgrounds. Statistically such students endure more disadvantage and are potentially less well informed than those who identify with the dominant culture. Culturally diverse students have been reported as experiencing more social isolation during the COVID-19 pandemic. Florez (2020) has identified that for those university students who have been both socially isolated and required to shift to online learning the negative burden has been immense.

\footnotetext{
${ }^{1}$ Money Smart, ASIC: https://moneysmart.gov.au/teaching-resources/be-moneysmart-module-1-saving-budgeting-andspending

2 Financial Basics Foundation: https://www.financialbasics.org.au/modules/
} 
In response, some tools were developed by LTSU during COVID-19. These included a series of financial wellbeing live webinars with expert panellists. Students on temporary visas who do not benefit from any Centrelink support were also provided expert information and live Q\&A access to panellists to respond to financial issues that were increasing anxiety, such as job insecurity and material aid needs. In addition to webinar information sessions, individual contact was provided via use of Zoom waiting room facilities to address private queries, console worries and refer for online casework support. Further connections were established through referral to student counselling, as well as referrals to cultural organisations or student clubs. This model could be used by other financial counsellors to enable client connection using telephone helplines or online community groups.

\section{How can mindfulness and meditation help students during COVID-19?}

A vital component of the Positive Psychology movement is the use of mindfulness and relaxation practice to open and focus the mind in order to enhance concentration, learn new skills, and importantly encourage the practice of relaxation during times of distress and isolation (Lomas, Hefferon, \& Ivtzan, 2014). During COVID-19, when other support is absent, mindfulness and meditation has been an accessible method to calm and centre the mind. Students faced with immediate and serious financial need can benefit from this practice to reduce reactivity, confusion and despair. Students may benefit from the calming effects derived from guided meditations ${ }^{3}$, or via referral to university or community counselling and wellbeing services.

In conclusion, while it may be challenging to adapt professional practice to suit these unusual times it is also rewarding to think creatively and to be inspired by strategies derived from positive psychology and Self-Determination Theory both of which are beneficial for the financial counsellor and the student who accesses their financial counselling practice. When incorporating these strategies into their practice the financial counsellor can acknowledge the resilience demonstrated by each student so far and encourage them to continue to learn and build their own skills and resources in order to combat their life challenges and live more resiliently. Financial counsellors already familiar with working to strengths are well placed in a client-centred practice to enable the character strengths of their student clients to be mobilised for greater wellbeing in these uncertain times of COVID-19.

\footnotetext{
${ }^{3}$ Smiling Mind: https://www.smilingmind.com.au/mindfulness; Headspace: https://www.headspace.com/science; Suncorp:https://www.suncorp.com.au/learn-about/health/what-makes-a-happy-person.html
} 


\section{References}

ASIC. (2020, April 10). Money Smart - student life and money. Retrieved from https://moneysmart.gov.au/student-life-and-money

CDS Database, Advocacy Dep't, LTSU. (2020). Client Report: Jan - July.

Florez, C. (2020, August 17). SBS News. Retrieved from SBS: https://www.sbs.com.au/news/australia-sinternational-students-are-going-hungry-with-60-per-cent-nowunemployed?cid=sbsnews:edm:newsam:relation:news:na:na

La Trobe University, Student Union. (2020, April 20). How can financial counselling help you as a student? Retrieved from La Trobe Student Union: https://latrobesu.org.au/financialcounselling

Lomas, T., Hefferon, K., \& Ivtzan, I. (2014). Applied positive psychology: integrated positive practice. Sage Publications.

Lyubomirsky, S., \& Sin, N. (2009). Enhancing well-being and alleviating depressive symptoms with positive psychology interventions: a practice-friendly meta-analysis. Journal of Clinical Psychology, 467-487.

Mindfit at work. (2020, May 12). Smiling mind. Retrieved from MindFit: https://www.mindfitatwork.com.au/

Niemiec, R. (2018). Character strengths interventions: A field guide for practitioners. Hogrefe.

Oades, L., Robinson, P., Green, S., \& Spencer, G. (2011). Towards a positive university. The Journal of Positive Psychology, 434.

Ryan, R., \& Deci, E. (2000). Self-determination theory and the facilitation of intrinsic motivation, social development, and well-being. American Psychologist, 68-70.

Seligman, M., \& Csikszenzentmihalyi, M. (2000). Positive psychology: An introduction. The American Psychologist, 55(1), 5-14.

Shukla, P. (2020, August 10). Impact of COVID-19 on students' mental health. Retrieved from Psychreg: https://www.psychreg.org/impact-of-covid-19-on-students-mental-health-and-well-being/

Suncorp. (2020, April 15). What really makes a happy person? Retrieved from Suncorp - money habits: https://www.suncorp.com.au/learn-about/health/what-makes-a-happy-person.html

VIA Institute of Character. (2020, April). Character strengths. Retrieved from https://www.viacharacter.org/

Wade, J., Marks, L., \& Hetzel, R. (2015). Positive psychology on the college campus. London: Oxford University Press.

\section{The author may be contacted}

r.angus@latrobe.edu.au

\section{Please cite this paper as:}

Angus, R., (2020). Can strengths-based interventions be used to support the financial wellbeing of tertiary students in financial need during COVID19? Journal of the Australian and New Zealand Student Services Association, 28(2), 96-101. doi.org.10.30688/janzssa.2020.08 